\section{Paradox of flying to meetings to protect the environment}

SIR - Scientists are becoming increasingly concerned about the environmental impact of their work. For example, in the latest of many recent reflections on the subject, bioinformatician Hervé Philippe urges us to uncouple scientific progress from economic growth (Trends Genet. 24, 265-267; 2008). He adds his voice to those advising us to reduce our carbon footprint by attending fewer scientific conferences (see also the Editorial 'Meeting expectations' Nature 455, 836; 2008).

Regular long-distance flying can easily triple an academic's carbon footprint. During the past year, I have 'spent' about nine tonnes of carbon, two-thirds of this on plane trips. Yet I am a good consumer otherwise (see www. carbonfootprint.com), and I don't even own a car. Such figures are particularly hard for field ecologists to stomach, as we hope our long-term work will highlight the environmental consequences of climate change and may ultimately influence the public and policy-makers.

Take, for instance, the dynamic field of conservation biology. Most of its best researchers are based at universities in the Northern Hemisphere, but most of their field sites are located in developing countries in the south. These hotshots and their students use up tonnes of fuel each year in commuting trips. In fact, those who are particularly renowned and most involved in environmental politics become 'constant fliers' who are always jetting off to field sites and meetings.

I estimate that such behaviour can potentially increase an individual's carbon footprint to ten times their national average. Of course, plenty of businessmen have similar or larger carbon footprints, but few of them would claim that their journeys are good

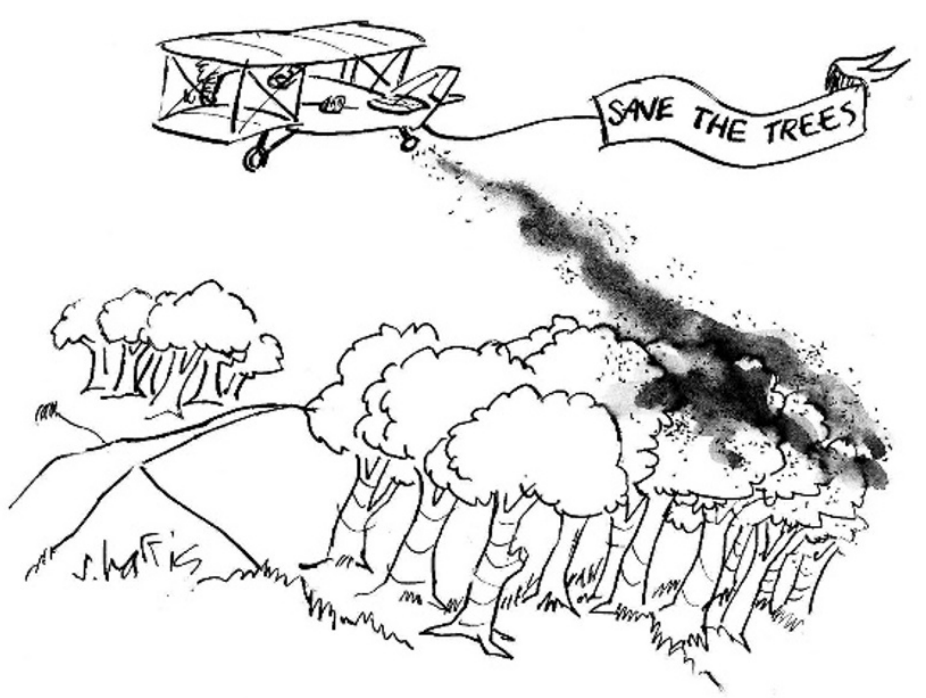

for the environment. One is left wondering whether the carbon footprints of ecologists outweigh the environmental benefits of their findings and of their lobbying.

One way around this problem is to promote conservation biology on site, with improved local academic training (see, for example, http://tinyurl. com/65kh9k), local research leaders and fewer but longer stays by foreign visitors. With regard to environmental politics, one faces the classic dilemma between personal restraint (I stay at home and work in the garden) and energy-demanding public involvement (I fly daily to help ban overfishing).

The outcome is a personal decision that may be dictated more by ambition than by environmental awareness. Nevertheless, as a German environmental campaigner told me 15 years ago, "Industry would be all too pleased if we did not attend distant meetings because we refuse to board aeroplanes."

David Grémillet Centre d'Ecologie Fonctionnelle et Evolutive - CNRS, 1919 route de Mende, F-34293 Montpellier, France, and FitzPatrick Institute of African Ornithology, University of Cape Town, Rondebosch 7701, South Africa e-mail: david.gremillet@cefe.cnrs.fr

Readers are welcome to comment at $h$ ttp://tinyurl.com/5hqhw.

\section{Science students need to develop the skills of artists}

SIR - In your 'Big data' issue, Felice Frankel and Rosalind Reid call for an "investment in visual communication training for young scientists" to prepare them for modern methods of data representation ('Distilling meaning from data' Nature 455, 30; 2008). But the problem goes deeper than that.

Graphic artists who collaborate with scientists have often been shaped by the other of C. P. Snow's 'two cultures'. Although well-intentioned, many artists' understanding of basic science is inadequate for meaningful participation in high-level technical work. Cognitive art is like commercial art and technical writing: it has never garnered respect from the artistic establishment, and its practitioners are left to fend for themselves.

From the start of schooling, distinctions are made between students with a talent for science and those with leanings towards the arts. In our technology-focused society, science receives more attention and an emphasis that does not include visual-thinking skills. Calculus, for example, is learned through symbolic operations, but portraying those procedures by using curves and surfaces and tangents and intercepts is typically considered to be an unnecessary frill.

Thus the two cultures diverge, and if we try to reassemble them later to let one benefit the other, we have serious difficulties: the world views don't match. Subjective ideas can be stifled by objective thought but, by the same token, physical reality can be mismanaged by well-meaning attempts at creativity.

We must indeed invest in visualization skills for sciencebound students, but there should be a parallel path for scienceillustrators-to-be to learn the basics of physics, chemistry and mathematics. Collaborators who understand each other's language have a much better chance of finding the common ground they need for the cooperation they seek.

Kenneth R. Jolls Chemical and Biological Engineering, lowa State University, 2114 Sweeney Hall, Ames, lowa 50011-2230, USA e-mail:jolls@iastate.edu

\section{Military government support of science in Pakistan is illusory}

SIR - Your Editorial 'After Musharraf' (Nature 454, 1030;

2008) seems biased in its comments on the role of elected governments in Pakistan. You note that the military has ruled the country for longer than civilians have, yet you blame civilian governments for the lack of development of science.

The military governments enjoyed unaccountable and unchallenged power. For example, they were not required to reveal details of their defence budgets, and military pensions were passed over to the civilian budget when international agencies applied pressure for the military budget to be cut down (using the argument that retired military personnel are civilians).

Under General Pervez Musharraf's rule, generals were 